\title{
The Ineffectiveness of Counterclaim Advertising for Increasing Consumer Sentiment
}

\section{(Short title: The Ineffectiveness of Counterclaim Advertising)}

Brent Coker (PhD, Victoria University Wellington)

Lecturer of Marketing, Department of Management and Marketing, The University of Melbourne, Victoria 3010, Australia (bcoker@unimelb.edu.au; Tel: +61-3-83441933).

Short Bio: Brent Coker's research focuses on consumer behaviour, and has been published in the Journal of Retailing, Journal of Economic Psychology, and the European Journal of Marketing to name a few. He currently teaches Digital Marketing and Social Media at the University of Melbourne at undergraduate, postgraduate, and executive education levels.

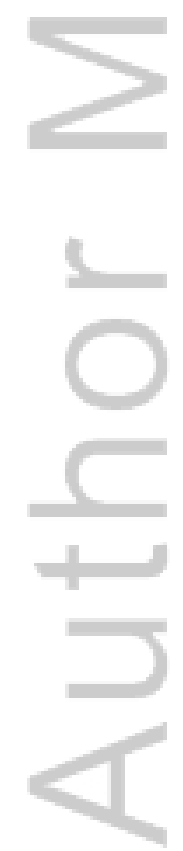

This is the author manuscript accepted for publication and has undergone full peer review but has not been through the copyediting, typesetting, pagination and proofreading process, which may lead to differences between this version and the Version of Record. Please cite this article as doi: $10.1002 /$ cb.1600

This article is protected by copyright. All rights reserved. 


\title{
The Ineffectiveness of Counterclaim Advertising for Increasing Consumer Sentiment
}

\begin{abstract}
When a brand is disliked, one strategy used to improve consumer sentiment is to make counter-claims against the reason for dislike. But little is known about the effectiveness of this strategy, or the effect this strategy has on differential judgments towards the brand. Two experimental studies are conducted to shed light on the effectiveness of counterclaim advertising. The results find evidence to suggest that counter-claim advertising may actually worsen sentiment towards the brand, when the brand is already disliked. The findings suggest that brands do not try to directly counter known reasons for dislike, but instead formulate alternative ways to rebuild trust.
\end{abstract}

Keywords: Counterclaim advertising, Sinister attribution error, brand dislike, persuasion 


\section{The Ineffectiveness of Counterclaim Advertising for Increasing Consumer Sentiment}

\section{Introduction}

Many consumers hold grudges towards brands (Smith, Bolton, and Wagner 1999). BP Oil for example is disliked because of the Deepwater Horizon oil spill. McDonalds is disliked by many because of their perceived contribution to obesity. One strategy disliked brands use to neutralize negative sentiment is to produce advertising messages that counter the reason for dislike. BP Oil for example produces advertisements that focus on caring for the environment, and McDonalds produces advertisements about healthier choices. But how do consumers react to brands who make claims that directly counter their reason for dislike? Does counterclaim advertising reduce negative sentiment? Or, despite sincere intentions from the brand, can counter-claim advertising backfire and actually worsen sentiment?

Attribution theory suggests that people are driven to make sense of events happening around them, and in doing so will use subjectively selected information believed to be causally related to the event (Fiske and Taylor 1991). Fundamental to attribution theory is that people make errors regarding the causes of events. For example, in social settings individuals will tend to explain other people's behaviour by attributing it to personality features rather than situational conditions (Folkes, Koletsky, and Graham 1987; Folkes 1984). Quite commonly people will attribute the causes of events to controllable internal factors rather than uncontrollable external factors (Weiner 1974; Jones et al. 1972).

When people make causal inferences to explain events, they often have incomplete information, and so to compensate may develop irrational thoughts. For example, Cowley (2005) demonstrated how consumers will tend to blame service providers for transgressions rather than their own disposition or situational constraints. In organisational settings Kramer (1994) demonstrated how people may develop thoughts of distrust and suspicion towards organisations when attention is focussed on the symptoms of their own distress rather than uncontrollable factors. He called this kind of error 'sinister attributions'. In the context of consumer behaviour, Main et al. (2007) demonstrated how consumers may develop irrational thoughts in sales settings, by finding evidence of sinister attributions forming from salesperson interactions preceding purchase.

Prior research suggests that attribution errors are extremely relevant to understanding consumer behaviour (Folkes, Koletsky, and Graham 1987; Folkes 1984; Main, Dahl, and Darke 2007). However, although there has been much research done to understand consumer responses to persuasion attempts by brands (Sujan, Bettman, and Sujan 1986; Wright 2002; Main, Dahl, and Darke 2007; Friestad and Wright 1994), little research has been done to understand how attribution errors may affect brand judgements through advertising. 
The present research aims to further understand consumer reactions to brands that use counter-argumentative advertising strategies. In light of previous research that has found evidence of sinister attributions forming in sales settings (Main, Dahl, and Darke 2007), we suggest that consumers may develop irrational and sinister attributions towards brands resulting from advertising, particularly when an advertising message from a disliked brand directly counters the reason for dislike. When a brand makes claims that directly counter what a consumer knows to be true, we suggest that the consumer will dislike the brand even more.

We test our proposition in two experimental studies. Study 1 demonstrates how an advertisement from a disliked brand can activate feelings of sinisterness towards the brand, despite sincere intentions. In study 2 we test how sinister attributions towards the brand can be activated through advertising counter-claims.

\section{Background}

Brands use advertising to persuade, and prior research suggests that consumers are generally aware that brands use deception to persuade them to buy (Craig et al. 2012). Consumers are also mostly aware of persuasion motives behind brand advertising, and it is not uncommon for consumers to feel distrustful as a result (Darke and Ritchie 2007; Forehand and Grier 2003; Obermiller, Spangenberg, and MacLachlan 2005). Generally, the efficacy of sales tactics reduces as consumers become more aware of attempts to influence their decision making (Brown and Krishna 2004; Campbell and Kirmani 2000).

Building on Wright's (1986) concept of "schemer schema," Friestad and Wright (1994) developed the persuasion knowledge model (PKM) to account for consumers' coping attempts when being persuaded. Brands try to persuade consumers using marketing messages, and over time learn more about what types of strategies and nuances in their advertising works best. Consumers also learn from the brand's advertising, developing an understanding of how reliable the brand is, and how to cope with the brand's attempts to persuade. The PKM framework suggests that consumers with high persuasion knowledge tend to be more in control of their responses to marketing communications than consumers with low persuasion knowledge, and therefore should be more difficult to persuade. When a consumer recognizes that marketing stimuli is designed to persuade, they will activate coping mechanisms which may include additional inferences, predictions, and response tactics. Ultimately, triggering persuasion knowledge can decrease the effectiveness of sales tactics by heightening consumers' awareness that they are the target persuasion (Brown and Krishna 2004; Campbell and Kirmani 2000). Activating these mechanisms can lead to scepticism against the source, or broader scepticism against the media in general (Obermiller, Spangenberg, and MacLachlan 2005).

According to attribution theory, people often assign reasons for an occurrence, and develop theories to explain the underlying causes that contributed to the occurrence (Heider 1958; Jones and Davis 1965; Kelley 1967). Doing so helps consumers to interpret events, and make sense of what is happening around them (Harvey and Weary 1984). In interpersonal relationships, judgments about a person's attempt to persuade may be anchored on their apriori expectations about the person's behaviour, and the extent to which subsequent or previous experience supports those expectations (Hardin 2004; Barber 1983). Thus, a person 
may reflect on reasons why a person is attempting to persuade them, and may impute irrational negative thoughts or attributions as a result (Main, Dahl, and Darke 2007).

Quite commonly, people make fundamental attribution errors (Cowley 2005), assigning reasons to another person's behaviour that turn out to be inaccurate (Srull and Wyer 1979). According to attribution theory, it is not uncommon for people to form paranoid thoughts towards others, believing that other people's actions have malevolent intentions when in reality they do not (Harvey and Weary 1984). One kind of fundamental attribution error is a tendency for people to over-attribute the intentions of others, leading to what is known as a "sinister attribution error" (Kramer 1994). For example, a consumer may assume a salesperson who compliments them in a store did so because they wanted them to make a purchase, not because they genuinely meant it (Main, Dahl, and Darke 2007).

$=$ According to research in advertising, when a marketing message is congruent to an individual's expectations and confirms their beliefs about the brand, they will adjust their attitude in a positive direction and are more likely to be persuaded by the message (Dahlen 2005; Edwards, Li, and Lee 2002; Russell 2002). Conversely, when a marketing message is incongruent to an individual's existing knowledge about a brand, they may assume injudicious intentions (Obermiller, Spangenberg, and MacLachlan 2005; Darke and Ritchie 2007). Therefore, in light of research that has examined the formation of sinister, irrational and distrustful attributions in sales settings (Main, Dahl, and Darke 2007; Cowley 2005; Folkes 1984), it is reasonable to speculate that consumers may develop sinister attributions towards brands, when claims made in the brand's advertisement are incongruent and counter the reason for brand dislike. Advertising messages that are incongruent to expectations should foster attribution errors, resulting in further resentment towards the brand when the brand is already disliked.

\section{Study 1}

In study 1 we developed an experimental procedure to determine if sinister attribution error could confound efforts by the brand to improve sentiment using counterclaim advertising. The assumption behind the procedure was that consumers may vary in the degree to which they like or dislike a brand (brand attitude). Thus, the strength of attitude towards any given brand was presumed to vary in accordance to the actions made by the brand (Madden, Allen, and Twible 1988).

Based on this assumption, we developed a priming procedure using positive or negative action-based hypothetical scenarios to activate high or low attitudes towards a brand. After manipulating participants' attitudes towards the brand using the prime, participants viewed an advertisement with claims that were either countering or consistent with the actions of the brand in each hypothetical scenario. Participants then completed several scales to evaluate how they reacted to the hypothetical actions of the brand. For each hypothetical scenario we measured attitudes towards the advertisement, persuasiveness of the advertisement, attitude towards the brand, and sinisterness. We predicted that in comparison to participants shown the positive action prime, those shown the negative action prime would 
develop sinister attributions, dislike the advertisement, and find the advertisement less persuasive.

\section{Method}

\section{Participants}

Three hundred and eighty-eight postgraduate and undergraduate students were invited to participate in the study through email. Entry into a prize draw to win a tablet computer was provided as an incentive. One hundred and twenty-two students participated, of which $70 \%$ were female, and $90 \%$ were undergraduates.

\section{Procedure}

In experimental research, it is preferable to separate the priming manipulation from the dependent variables. Therefore, participants were told that they would be involved in two separate studies. The first study was described as a pilot study for a project that was examining service delivery in the banking sector. The second study was described as part of a project examining the quality of advertisements. To reinforce independence between each study, different names were given for the lead investigators, and research materials in each study were produced using different fonts (serif versus sans-serif typefaces).

Participants were randomly split into two groups of equal size (positive versus negative brand action prime). Each group was then instructed to read a scenario about the actions of a bank brand, and answer several questions designed to activate a strong opinion about the actions. In the negative brand action prime, the scenario described a bank that had delivered a poor experience for its customers, including negative comments from customers who had been affected by the poor experience. After they read the scenario, participants were instructed to answer two open-ended questions designed to further activate negative thoughts towards the bank brand ("Think about a time you have received poor service from a bank, and describe how you can relate to the customers comments on this page"; "Describe what you feel is a terrible experience from a bank").

Participants in the positive brand action prime group read a scenario about a bank that had provided a positive customer experience, including positive customer comments from satisfied customers regarding their encounter with the bank. They answered two open-ended questions designed to activate positive thoughts about the brand ("Think about a time you received good service from a bank, and describe how you can relate to the customers comments on this page"; "Describe a time when you were extremely impressed with your interaction with a bank").

At the conclusion of "study 1", part 2 of the study commenced. Participants were told the purpose of part 2 was to examine advertising quality, though were told it was a separate study. Each group was shown a video advertisement from a bank, where the message was about the bank's pride in delivering superior service to their customers. The advertisement 
featured a bank employee explaining how his bank takes time to explain and tailor banking services. The actor makes a comparison between superior customer service and a small cake, claiming that the bank's service is great on the surface as well as the inside. The advertisement was from a real state bank in the USA, and had not been shown previously in the country the study was conducted (Australia).

After the advertisement was shown, all participants completed 7-point scales. Attitudes towards the advertisement was measured using a four item semantic differential type scale including: Uninteresting /Interesting; unfavourable/favourable; unenjoyable/enjoyable; bad/good; $\left.\alpha_{\text {pos }}=.74 ; \alpha_{\text {neg }}=.84\right)$. This scale has been used in a number of studies to measure attitudes towards an advertisement (Kirmani 1990; Lutz, MacKenzie, and Belch 1983; Stout and Burda 1989; Machleit and Kent 1989; Madden, Allen, and Twible 1988; Shimp and Yokum 1981). Persuasiveness of the advertisement was measured by asking how persuasive they thought the advertisement was (not at all persuasive/very persuasive). Attitude towards the bank brand in the hypothetical scenarios was measured using a standard three item sematic differential scale developed to measure general attitudes towards an object or entity (Ajzen 2005): negative/positive; undesirable/desirable; bad/good ( $\alpha_{\text {pos }}=.91 ; \alpha_{\text {neg }}=$ 95). To evaluate the effectiveness of the brand attitude prime, attitude towards the bank brand in the hypothetical scenarios was measured using the same items (negative/positive; undesirable/desirable; $\mathrm{bad} / \mathrm{good} ; \alpha_{\mathrm{pos}}=.91 ; \alpha_{\text {neg }}=.95$ ).

To measure sinisterness, we used three items: "This brand is deviant" "This brand is sinister"; and, "This brand is dishonest". From a theoretical perspective, the construct of 'sinisterness' includes attributions of distrust and dishonesty (Kramer 1994, 1999). The construct of sinisterness is also characterised by thoughts of deviousness (Main, Dahl, and Darke 2007; Bennett and Robinson 2000). Factor Analysis (principle axis factoring with Varimax rotation) was estimated to evaluate the suitability of combining the items into a single 'sinisterness' factor for further analysis, and integrity of the structural properties of the construct. The results of the factor analysis found significant correlations between the items ranging between 0.47 and 0.53 . Generally, correlations exceeding .30 suggest sufficient commonality to combine the items into a single measure (Tabachnick and Fidell 2001). Bartlett's test was .69 suggesting the sample size was adequate $\mathrm{p}<.001$, and the matrix determinant was .49 suggesting multicollinearity wasn't an issue. The factor matrix suggested the three items could be reasonably combined into a unitary factor, with an eigenvalue of 2.01 explaining $67 \%$ of the total variance (the next factor eigenvalue was .5, below Kaiser's (1960) criterion of retaining factors with eigenvalues greater than 1). Therefore, the three item scores were combined for the analysis $\left(\alpha_{\mathrm{pos}}=.75 ; \alpha_{\text {neg }}=.81\right)$.

At the end of the studies, participants were debriefed and thanked for their participation. During the debriefing, we probed for suspicion that the two studies were linked in some way. There was no suggestion that any of the participants perceived a link between the hypothetical scenario study, and the advertisement study. There was also no knowledge amongst participants that there were two different hypothetical scenarios, and no-one had seen the advertisement before the experiment. 


\title{
Results
}

\section{Manipulation Checks}

To determine the effectiveness of the priming manipulations, a one-way ANOVA was estimated on the manipulation check variable measuring brand attitude. The analysis revealed a significant main effect of the brand attitude prime. Participants reported more negative attitudes towards the bank brand characterized by a negative customer experience $(M=3.86$, $S D=1.30)$ than the bank characterized by a positive customer experience $(M=5.50, S D=$ $1.80), F(1,121)=33.53, p<.001$. This suggested the priming procedure was successful.

\section{Hypothesis tests}

To evaluate the main effects of the brand attitude prime, we analysed all dependent variables simultaneously, with the independent brand attitude variable as a between subject's factor. Compared with participants in the high brand attitude prime condition $(M=3.59, S D=1.27)$, those in the low brand attitude prime condition thought the brand behind the advertisement was more sinister $(M=4.50, S D=1.22), F(1,121)=16.56, p<.001$.

Participants in the low brand attitude prime condition also exhibited lower attitudes towards the brand in the advertisement $(M=4.15, S D=1.40)$ than those in the high brand attitude prime condition $(M=4.88, S D=1.17), F(1,121)=9.78, p<.01$, and lower overall attitude towards the advertisement $(M=3.32, S D=1.22 ; M=3.97, S D=1.33), F(1,121)=$ $8.05, p<.01$. Participants also thought the advertisement was less persuasive in the negative brand attitude prime condition $(M=3.39, S D=1.43)$ than in the positive attitude prime condition $(M=4.18, S D=1.39), F(1,121)=9.54, p<.01$. Figure 1 and Table 1 summarizes these results.

\section{[Insert figure 1 about here]}

\author{
[Insert Table 1 about here]
}

Given that $70 \%$ of the sample were female, we also analysed each gender separately to determine if gender might moderate the main effects. We did not find any significant differences between each gender (males: sinisterness $F(1,35)=6.38, \mathrm{p}<.05 ; M_{\mathrm{lo}}=4.52, S D$ $=1.22 ; M_{h i}=3.36, S D=1.16$; brand attitude $F(1,35)=9.86, \mathrm{p}<.01 ; M_{\mathrm{lo}}=3.71, S D=1.47$; $M_{h i}=5.08, S D=1.16$; Attitude towards the advertisement $F(1,121)=3.61, \mathrm{p}=.07 ; M_{\mathrm{lo}}=$ 2.73, $S D=1.17 ; M_{h i}=3.47, S D=1.15$; persuasiveness $F(1,35)=5.25, \mathrm{p}<.05 ; M_{\mathrm{lo}}=3.44$, $S D=1.20 ; M_{h i}=4.03, S D=1.46$. Females: sinisterness $F(1,85)=9.59, \mathrm{p}<.01 ; M_{\mathrm{lo}}=4.50$, $S D=1.23 ; M_{h i}=3.70, S D=1.18$; brand attitude $F(1,85)=3.24, \mathrm{p}=.08 . M_{\mathrm{lo}}=4.28, S D=$ $1.37 ; M_{h i}=3.97, S D=1.33$; Attitude towards the advertisement $F(1,85)=6.38, \mathrm{p}<.05 ; M_{\mathrm{lo}}$ $=3.52, S D=1.18 ; M_{h i}=4.21, S D=1.36$; persuasiveness $F(1,85)=4.44, \mathrm{p}<.05 ; M_{\mathrm{lo}}=3.38$, 
$S D=1.38 ; M_{h i}=4.02, S D=1.46$

\section{Discussion}

The results find evidence for our prediction that consumers may form sinister attributions towards a brand when advertising claims counter existing knowledge structures. When primed to have low attitudes towards banks, participants thought the persuasive attempts by the bank in the advertisement were more sinister than when primed to have positive attitudes towards the brand. Thus, our hypothesis predicting that sinister attribution error could occur when the theme of an advertisement was directly counter to the reason for disliking the brand was supported.

The results also found that attitudes towards the brand and the advertisement were lower when participants were primed to have negative attitudes towards bank service quality. This suggests that the thought processes of participants regarding attitudes towards the brand and advertisement were irrational, since the priming task was separate to the actual bank brand in the advertisement shown. We interpret this to mean that when there is a motive to persuade, consumers may incorrectly attribute mediating information as relevant to the persuasion motive, even though evidence to suggest the mediating information is tied to the persuasion motives does not exist. This interpretation is consistent with Main et al. (2007) who demonstrated irrational sinister attributions formed towards salespeople when flattery was given before a sale rather than after a sale. Our findings provide further evidence to suggest that persuasion knowledge may lead to consumers making assumptions about brands that are not always warranted.

Our results suggest that participants resented the banks persuasion efforts, since participants in the low brand prime condition formed lower attitudes towards the brand, as well as lower attitudes towards the advertisement. This suggests that when brands attempt to regain consumer's trust and improve negative sentiment, using advertising claims that directly counter the reason for dislike might actually worsen sentiment, by activating attributional beliefs that the brands efforts to persuade are disingenuous.

\section{Study 2}

Study 1 reveals evidence of sinister attribution error as a result of counterclaim advertising when the brand is disliked. The priming procedure negatively affected evaluations of the advertisement's likability and persuasiveness. However, the priming procedure was artificial, and did not directly test the association between a disliked brand and sinister attribution from the same brand, as would occur in real-world circumstances. In study 2 we used an actual brand that was already disliked by participants.

We first conducted a pretest survey to discover two brands that were disliked for a common reason. After some time, the author contacted the same participants who participated in the pretest to take part in the main experiment. In the main experiment, participants were 
shown an artificially produced video advertisement from the brand with a message that was counter to the reason for disliking the brand. Thus, if a participant indicated that they disliked a brand because of poor value (monetary), then we showed them an advertisement from the brand that made claims about offering good value for money. If a participant disliked a brand because they had experienced poor service, then we showed them an advertisement that made claims about giving good service. We included two more conditions with separate groups where the claims in the advertisement were not the same as the reason for disliking the brand. Thus, the design was a 2 (value, service) $\times 2$ (poor value ad/poor service ad) between subject's design.

We expected to find evidence of sinister attributions for those who were exposed to an advertisement where the claims in the advertisement were the same as the reason for disliking the brand.

The design also included scales to measure the recency of brands transgression, and duration of brand relationship. This was to identify whether participants might be more likely to forgive brands if the transgression had occurred a long time in the past. Similarly, participants who had a relatively long relationship with a brand might have been more likely to forgive the brand. Finally, we measured severity of transgression leading to brand dislike, since an individual who had a relatively minor reason for disliking the brand might be less likely to exhibit signs of sinister attributions.

\section{Method}

\section{Participants}

Participants were 162 postgraduate students from the business school Master's Program, of which $57 \%$ were female. Participants were entered into a prize draw to win a tablet computer in return for participating in both phases of the study. Sign-up information about the study indicated that all participants must have had an experience with a brand where their expectations had not been met, or where they had been let down by the brand.

\section{Procedure}

Participants were told that the goal of the study was to explore the effectiveness of advertising. The study commenced in two stages, separated by 2 weeks. In the first stage (pretest), the aim was to identify participants who disliked any brand for a common reason. All participants were instructed to think about a brand they had purchased from sometime in the past, where the outcome of the interaction was a negative experience. This was achieved by asking them the following questions: (1) Think of a brand you have purchased from in the past (product or service), where the brand let you down, or did not meet your expectations. Name the brand here. (2) Describe in as much detail as you can how the brand let you down, or why the brand did not meet your expectations (3) How much do dislike the brand as a 
result of your experience? (7-point scale, $1=$ strongly dislike; 7 = I don't dislike the brand); $(M=3.15 ; S D=1.40)$.

Participants $(n=14)$ who indicated that they did not dislike the brand they named were dismissed from participating in part two of the study, and their questionnaires were not included in further analysis. Copies of the remaining completed questionnaires $(n=148)$ were then given to two research assistants who were instructed to sort them into piles based on common reasons for disliking the brand. Inter-rater agreement between the judges was acceptable $(\kappa=.81)$. Where disagreement arose for any given questionnaire, a third judge was employed to make the decision on which pile the questionnaire belonged. After sorting, the two largest piles (most common reasons for disliking the brand) were used in phase 2 of the study. Of those, 51 respondents indicated that they disliked a brand because they provided poor customer service (e.g., "The staff were incredibly rude..."), and 34 indicated that they disliked the brand because their prices were too high (e.g., "I feel like I was ripped off. I ended up paying way too much..."). Participants whose reason for disliking the brand was other than price or service related were thanked, dismissed, and not invited to participate in phase 2 of the study. Their questionnaires were not included in any further analysis.

The second stage of the study commenced after two weeks. Respondents who indicated they disliked a brand because of high prices or poor service were split into two groups based on their reason for dislike ("price" and "service"). Two TV advertisements not previously shown in the country (Australia) were professionally edited to remove any reference to the brand. Both advertisements showed the brands at the end using a delayed brand exposure technique, and therefore the brands could be removed without affecting the message and story. One of the advertisement messages was about giving good value for money, and the other advertisement message was about providing good service. The value for money advertisement featured a men's room attendant who went to extra lengths to help the patrons, comically more than would be expected. The price advertisement featured a split screen with the same customer in each screen, though on one side eating a nice meal, and on the other side eating a basic cheap meal as a result of a recent purchase.

The price group was randomly split into two groups, and separated from each other. One of the price groups was shown the advertisement about providing good value for money, and the other price group was shown the advertisement about providing good service.

The service group was also randomly split into two groups, with one of the service groups shown the advertisement about providing good service, and the other service group shown the advertisement about providing poor value for money.

After watching the advertisements, all participants were instructed to imagine the advertisement was actually from the brand they reported in phase one of the study (Tversky and Kahneman 1983). All participants then completed self-report 7-point scales, including: attitudes towards the advertisement (Interesting/uninteresting; unfavourable/favourable; unenjoyable/enjoyable; bad/good; $\alpha=.84$ ), persuasiveness of the advertisement (not at all persuasive/very persuasive), and sinisterness ("This brand is deviant" "This brand is sinister"; "This brand is dishonest"; $1=$ strongly disagree, $7=$ strongly agree; $\alpha=.71$ ). Respondents were also asked an open ended question about the advertisement: "What do you think the brand's key message is with this advertisement?" to check whether the key message of providing good value or service was perceived. Finally, to test for possible confounding 
effects from brand forgiveness, participants were asked how long ago they had the negative experience with the brand ( $1=$ a very long time ago; $7=$ just recently) and how many times they had interacted with the brand for purchasing $(1=$ just once; $7=$ many times $)$.

\section{Results}

\section{Advertisement message check}

All respondents when asked to describe the main message of the advertisement indicated that it was about giving good service, or providing good value for money ("good prices") respectively. None of the participants indicated that they had seen either of the advertisements before.

Effects of Sinisterness, advertisement attitude, advertisement persuasiveness, and brand attitude

To evaluate the overall effects of advertisement message on sinisterness, ad attitude, ad persuasiveness, and brand attitude, we analysed all dependent variables simultaneously. Participants who viewed the advertisement message that was the same as their reason for disliking the brand exhibited higher perceptions of sinisterness $(M=4.99, S D=1.22)$, than participants who viewed the advertisement message that was different to the reason why they disliked the brand $(M=3.92, S D=1.12), F(1,84)=17.62, p<.001$.

Participants who viewed the advertisement message that was the same as their reason for disliking the brand exhibited lower overall attitude towards the advertisement $(M=3.48$, $S D=1.28)$ than participants who viewed the advertisement message that was different to the reason why they disliked the brand $M=4.58, S D=1.05), F(1,84)=18.60, p<.001$, and perceived the advertisement to be less persuasive $(M=3.09, S D=1.28 ; M=3.81, S D=1.15)$, $F(1,84)=7.41, p<.01$. The overall analysis revealed a significant interaction of ad message $\times$ reason for brand dislike, $F(1,84)=20.77, p<.001$. The interaction is presented in figure 2 .

[Insert figure 2 about here]

To explore whether the association between reason for brand dislike and same ad message and sinister attributions could be confounded by recency of transgression and frequency of brand interaction, we performed analysis of covariance. The results found no significant effect for recency of transgression $(\mathrm{F}=1.4, \mathrm{~ns})$ or duration of brand relationship ( $\mathrm{F}$ $=0.75, \mathrm{~ns}$ ). With these covariates included in the analysis, the effect of reason for brand dislike and brand message on sinister attributions remained significant $F(1,84)=6.40, p<$ .05 . 


\section{Discussion}

These results suggest our hypothesis predicting that sinister attribution error could occur when the theme of an advertisement was directly counter to the reason for disliking the brand was supported. The results are summarized in Table 1.

[Insert table 1 about here]

The findings in Study 2 show that consumers developed sinister attributions when the message of the advertisement was directly countering the reason for disliking the brand. Participants who disliked the brand because of perceptions of poor value, and who watched an advertisement from the brand about giving good value, felt the brand was sinister. They also exhibited relatively lower attitudes towards the advertisement, perceiving it to be less persuasive than participants who viewed an advertisement with a message not directly addressing the reason for disliking the brand. Given similar results were found when we analysed each brand dislike reason separately (Table 1) external validity is added to our findings.

\section{General Discussion}

Counter-claim advertising remains a common strategy for brands seeking to neutralize negative sentiment and perhaps seek forgiveness from disgruntled consumers. But little is known about the persuasive effectiveness of advertisements that use this strategy, or the effect this strategy has on differential judgments towards the brand. This research contributes to our understanding of brand judgments by showing how advertisements using counter-claims to mitigate negative sentiment towards a brand may have the unintended effect of deteriorating negative sentiment even further. In study 1 we demonstrate evidence of sinister attributions affecting judgments towards the brand, when the reason for disliking the brand is counter to the claims made in the advertisement. In study 2, using actual pre-existing brand disgruntlements, we demonstrate how these effects are not confounded by recency of brand transgression or duration of relationship with the brand.

The findings in the present research are consistent with prior research that has found that people may irrationally assume a person's communications are sinister when there is no evidence to suggest the person has any ulterior motive (Main, Dahl, and Darke 2007). Prior research has also found that a communicator's perceived honesty depends on the message source content, and that people will tend to scrutinize a message more when the communicator is perceived as untruthful (Priester and Petty 1995). Building on these findings, the present research demonstrates how judgments towards advertisements may evoke sinister attributions when the message of the advertisement should otherwise be perceived as positive.

The results of both studies suggest that consumers draw on existing knowledge when evaluating brand messages. The effect existing knowledge has on brand evaluation is moderated by advertisement message congruency between the reason for disliking the brand, 
and the brand message. Our analysis suggests that when the brand message is counter to existing knowledge about the brand, consumers elaborate and form additional thoughts of sinisterness, which may be construed as irrational suspicion. Moreover, brands might evoke paranoid suspicion in consumers' thought processes by attempting to directly address known reasons for discontent. This reasoning is consistent with the sinister attribution error theory documented by Kramer (1999).

There are theoretical and practical implications resulting from the findings in this study. Theoretically, the present findings extend research on paranoid cognition in the marketplace. Whereas past research has found some evidence of irrational distrust in interpersonal relationships (e.g., Main, Dahl, and Darke 2007), the present findings show evidence to suggest irrational distrust may also occur towards marketing messages. The present findings also contribute towards understanding of judgment formation towards advertisements (e.g., Meyers-Levy and Malaviya 1999), by identifying a situation where consumers may readjust initial judgments towards a brand. This readjustment lowers perceptions of persuasiveness of advertisements. Attribution error has been found to increase under cognitive load (Gilbert 1989), suggesting that reasoning and thoughtful processing might reduce the chances of the error occurring, increasing the accuracy of the interpretation. Groupthink, or reference to a majority conclusion about the action of another could be another way to reduce sinister attribution error (Marr et al. 2012). We therefore suggest that future research should focus on these phenomena in an effort to identify neutralizing conditions.

In terms of implications for practice, this is the first study to investigate how sinister attributions might confound efforts to improve customer sentiment through using counterclaims in advertising. Our findings suggest that brands might do more harm than good when trying to repair negative sentiment towards them using advertising. Accordingly, brands should exercise caution when considering using counter-claim advertising to repair or neutralize negative sentiment. The results suggest that brands do not try to directly counter known reasons for dislike, but instead formulate alternative ways to rebuild trust. Our contribution provides insights to brand managers contemplating corrective and preventative advertising measures against negative brand sentiment.

There are some limitations of our study. Although we believe we improve the external validity of our findings in study two by asking participants to recall a brand from past experience, by design the procedure requires participants to remind themselves of their past experience with the brand prior to forming judgements about the brand. In practice we would not necessarily expect consumers to explicitly remind themselves about past dealings with a brand when making judgements, and therefore we cannot be sure about the demand effects of recency on our findings. We suggest that a more careful examination of the recency of brand transgressions as affecting brand judgments in response to counter-claim advertising would be an important line of further investigation on this topic. We also note that our sample were students, and suggest a further important line of future research in this area should consider different age groups to validate and assess the generalisability of our findings. 


\section{Literature Cited}

Ajzen, Icek. 2005. Attitudes, Personality and Behavior. 2nd ed. Maidenhead: UK: Open University Press.

Barber, B. 1983. The Logic and Limits of Trust. New Brunswick, NJ: Rutgers University Press.

Bennett, Rebecca J., and Sandra L. Robinson. 2000. Development of a Measure of Workplace Deviance. Journal Of Applied Psychology 85 (3):349-60.

Brown, Christina L, and Aradhna Krishna. 2004. The Skeptical Shopper: A Metacognitive Account for the Effects of Default Options on Choice. Journal of Consumer Research 31:529-39.

Campbell, Margaret C., and Amna Kirmani. 2000. Consumers' Use of Persuasion Knowledge: The Effects of Accessibility and Cognitive Capacity on Perceptions of an Influence Agent. Journal of Consumer Research 27 (June):69-83.

Cowley, Elizabeth. 2005. Views from consumers next in line: The fundamental attribution error in a service setting. Journal of the Academy of Marketing Science 33 (2):139152.

Craig, Adam W., Yuliya Komarova Loureiro, Stacy Wood, and Jennifer M.C. Vendemia. 2012. Suspicious Minds: Exploring Neural Processes During Exposure to Deceptive Advertising. Journal of Marketing Research 49 (3):361-372.

Dahlen, M. 2005. The Medium as a Contextual Cue. Journal of Advertising 34 (3):89-98.

Darke, Peter R., and Robin J. B. Ritchie. 2007. The Defensive Consumer: Advertising Deception, Defensive Processing, and Distrust. Journal of Marketing Research 44 (1):114-127.

This article is protected by copyright. All rights reserved. 
Edwards, S. M, H Li, and J.-H Lee. 2002. Forced Exposure and Psychological Reactance: Antecedents and Consequences of the Perceived Intrusiveness of Pop-Up Ads. Journal of Advertising 31 (3):83-96.

Fiske, S. T, and S. E Taylor. 1991. Social cognition. 2nd ed. New York: McGraw-Hill.

Folkes, Valerie, Susan Koletsky, and John Graham. 1987. A Field Study of Causal Attributions and Consumer Reaction: The View From an Airport. Journal of Consumer Research 13:534-539.

Folkes, Valerie S. 1984. Consumer Reactions to Product Failure: An Attributional Approach. Journal of Consumer Research 10:398-409.

Forehand, Mark R, and Sonya A Grier. 2003. When Is Honesty The Best Policy? The Effect of Stated Company Intent on Consumer Skepticism. Journal of Consumer Psychology 13 (3):349-356.

Friestad, Marian, and Peter Wright. 1994. The persuasion knowledge model: How people cope with persuasion attempts. Journal of Consumer Research 21 (1):1-32.

Gilbert, D. T. 1989. Thinking lightly about others: Automatic components of the social inference process. In Unintended thought edited by J. S. Uleman and J. A. Bargh. New York: Guilford Press.

Hardin, R. 2004. Distrust. New York: NY: Russell Sage Foundation.

Harvey, J. H, and G. Weary. 1984. Current issues in attribution theory and research. Annual Review of Psychology 35:427-459.

Heider, Fritz. 1958. The Psychology of Interpersonal Relations. New York Wiley.

Jones, E. E, D. E. Kannouse, H. H. Kelley, R. E. Nisbett, S. Valins, and B. Weiner. 1972. Attribution: Perceiving the Causes of Behavior. Morristown, NJ: General Learning Press. 
Jones, E. E. , and K. E. Davis. 1965. From acts to dispositions: the attribution proces in social psychology. In Advances in experimental social psychology, edited by L. Berkowitz. New York: Academic Press.

Kaiser, H. F. 1960. The application of electronic computers to factor analysis. Educational and Psychological Measurement 20:141-151.

Kelley, H. H. 1967. Attribution theory in social psychology. In Nebraska Symposium on Motivation edited by D. Levine. Lincoln: University of Nebraska Press.

Kirmani, A. 1990. The effects of perceived advertising costs on brand perceptions. Journal of Consumer Research 17:160-171.

Kramer, Roderick M. 1994. The Sinister Attribution Error: Paranoid Cognition and Collective Distrust in Organisations. Motivation and Emotion 18 (2):199-230.

Kramer, Roderick M. 1999. Trust and Distrust in Organizations: Emerging Perspectives, Enduring Questions. Annual Review of Psychology 50:569-98.

Lutz, R. J, S. B MacKenzie, and G. E Belch. 1983. Attitude toward the Ad as a mediator of advertising effectiveness: Determinants and consequences. In Advances in Consumer Research, edited by R. P. Bagozzi and A. M. Tybout. Ann Arbor: MI: Association for Consumer Research.

Machleit, K. A, and R. J Kent. 1989. What is the effect of attitude toward the Ad when the consumer is familiar with the brand? Paper read at AMA Educators' Proceedings.

Madden, T. J, C. T Allen, and J. L Twible. 1988. Attitude toward the Ad: An assessment of diverse measurement indices under different processing sets. Journal of Marketing Research 25:242-252.

Main, Kelley J., Darren W. Dahl, and Peter R. Darke. 2007. Deliberative and Automatic Bases of Suspicion: Empirical Evidence of the Sinister Attribution Error. Journal of Consumer Psychology 17 (1):59-69.

Marr, Jennifer Carson, Stefan Thau, Karl Aquino, and Laurie J. Barclay. 2012. Do I want to know? How the motivation to acquire relationship-threatening information in groups 
contributes to paranoid thought, suspicion behavior, and social rejection.

Organizational Behavior and Human Decision Processes 117:285-297.

Meyers-Levy, Joan, and Prashant Malaviya. 1999. Consumers' Processing of Persuasive Advertisements: An Integrative Framework of Persuasion Theories. Journal of Marketing 63 (4):45-60.

Obermiller, Carl, Eric Spangenberg, and Douglas L. MacLachlan. 2005. Ad Skepticism: The Consequences of Disbelief. Journal of Advertising 34 (3):7-17.

Priester, Joseph R., and Richard E. Petty. 1995. Source Attributions and Persuasion: Perceived Honesty as a Determinant of Message Scrutiny. Personality and Social Psychology Bulletin 39 (6):637-654.

Russell, C. A. 2002. Investigating the Effectiveness of Product Placements in Television Shows: The Role of Modality and Plot Connection Congruence on Brand Memory and Attitude. Journal of Consumer Research 29 (December):306-318.

Shimp, T. A, and J. T Yokum. 1981. The influence of deceptive advertising on repeat purchase behavior. Paper read at AMA Educators' Proceedings.

Smith, Amy K., Ruth N. Bolton, and Janet Wagner. 1999. A Model of Customer Satisfaction with Service Encounters Involving Failure and Recovery. Journal of Marketing Research 36 (3):356-372.

Srull, T. K, and R. S Wyer. 1979. The role of category accessibility in the interpretation of information about persons: Some determinants and implications. Journal of Personality and Social Psychology 37 (10):1660-1672.

Stout, P. A, and B. L Burda. 1989. Zipped commercials: Are they effective? Journal of Advertising 18:23-32.

Sujan, M, J. R Bettman, and H Sujan. 1986. Effects of consumer expectations on information processing in selling encounters. Journal of Marketing Research 13:346-353.

Tabachnick, B, and L Fidell. 2001. Using multivariate statistics. Needham Heights: Allyn \& Bacon.

This article is protected by copyright. All rights reserved. 
Tversky, A, and D Kahneman. 1983. Availability: A heuristic for judging frequency and probability. Cognitive psychology 5:207-232.

Weiner, B. 1974. Achievement motivation and attribution theory. Morristown, N.J: General Learning Press.

Wright, Peter. 1986. Schemer schema: Consumers' intuitive theories about marketers' influence tactics. Advances in consumer research.

Wright, Peter. 2002. Marketplace metacognition and social intelligence. Journal of Consumer Research 28:677-683.

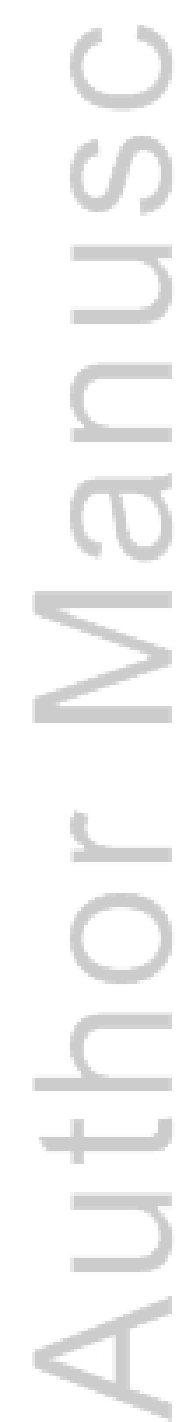

This article is protected by copyright. All rights reserved. 
Table 1. Differential reactions to the brand based on positive or negative sentiment priming

\begin{tabular}{|c|c|c|c|c|}
\hline & & Mean & SD & $F(1,121)$ \\
\hline \multirow[t]{2}{*}{ Brand Attitude } & Negative Prime & 4.13 & 1.40 & \multirow{2}{*}{$10.20 * *$} \\
\hline & Positive Prime & 4.88 & 1.17 & \\
\hline \multirow[t]{2}{*}{ Sinisterness } & Negative Prime & 4.50 & 1.21 & \multirow{2}{*}{$16.56 * * *$} \\
\hline & Positive Prime & 3.59 & 1.27 & \\
\hline \multirow{2}{*}{ Brand attitude } & Negative Prime & 3.32 & 1.22 & \multirow{2}{*}{$8.05^{* *}$} \\
\hline & Positive Prime & 4.00 & 1.33 & \\
\hline \multirow[t]{2}{*}{ Persuasiveness } & Negative Prime & 3.39 & 1.43 & \multirow{2}{*}{$9.54 * *$} \\
\hline & Positive Prime & 4.18 & 1.39 & \\
\hline
\end{tabular}

Note. The possible range for each variable is from 1 to 7 . The $F$ column presents $F$ statistics for the effect. ${ }^{* *} p<.01 ;{ }^{* * *} p<.001$.

Table 2. Reactions to the advertisement as a function of brand dislike reason and advertisement message

\begin{tabular}{|c|c|c|c|c|}
\hline \multirow[b]{2}{*}{$\begin{array}{l}\text { Advertisement } \\
\text { perceptions }\end{array}$} & \multicolumn{4}{|c|}{ Reason for brand dislike } \\
\hline & $\begin{array}{c}\text { Service } \\
\text { ad }\end{array}$ & $\begin{array}{c}\text { Price } \\
\text { ad }\end{array}$ & $r$ & $F(1,23)$ \\
\hline Sinisterness & 4.81 & 3.59 & 0.5 & $11.02 * *$ \\
\hline Persuasiveness & 3.31 & 4.06 & 0.3 & 3.81 \\
\hline \multirow{2}{*}{ Likability } & 3.26 & 4.31 & 0.4 & $7.45^{* *}$ \\
\hline & \multicolumn{4}{|c|}{ Poor Value } \\
\hline Sinisterness & 4.15 & 5.27 & 0.5 & $9.76^{* *}$ \\
\hline Persuasiveness & 3.64 & 2.76 & 0.4 & $5.65^{*}$ \\
\hline Likability & 4.76 & 3.82 & 0.4 & $7.71^{* *}$ \\
\hline \multicolumn{5}{|c|}{$\begin{array}{l}\text { Note. Values in the Service ad (participants who watched the } \\
\text { service advertisement) and Price ad (participants who } \\
\text { watched the value advertisement) are means for each } \\
\text { condition. The possible range for each variable is from } 1 \text { to } 7 \text {. } \\
\text { The } r \text { column presents effect size, and the } F \text { column presents } \\
F \text { statistics for the effect. }{ }^{*} p<.05 ;{ }^{*} p<.01 \text {. }\end{array}$} \\
\hline
\end{tabular}




\section{University Library}

\section{- M M N E R VA A gateway to Melbourne's research publications}

Minerva Access is the Institutional Repository of The University of Melbourne

Author/s:

Coker, B

Title:

The ineffectiveness of counterclaim advertising for increasing consumer sentiment

Date:

2017-01-01

Citation:

Coker, B. (2017). The ineffectiveness of counterclaim advertising for increasing consumer sentiment. JOURNAL OF CONSUMER BEHAVIOUR, 16 (1), pp.34-41. https:// doi.org/10.1002/cb.1600.

Persistent Link:

http://hdl.handle.net/11343/291640 